\title{
Human Services Information Technology, A Shared System
}

\author{
Charles R. Winer and Thomas W. Pavkov \\ Purdue University Calumet, USA
}

\author{
Winer@calumet.purdue.edu and tpavkov@nwi.calumet.purdue.edu
}

\begin{abstract}
From surveyed responses and evolving technologies, technical issues related to developing a secure county/regional based human services information systems solution are identified. Components of such a system are identified and discussed as to their viability to successfully design and implement shared data between government agencies and non-profit groups throughout Lake County and the State of Indiana. Some of these components are a common intake function, master client/family index to including client education, training and history components, a master provider index, case coordination/management system, and the use of E-forms to reduce traditional paper processing and encourage more efficient usage of data storage and retrieval technologies within a clientcentric environment.
\end{abstract}

Keywords: clientcentric, data warehouse, enterprise server, Virtual Private Network (VPN), middleware

\section{Introduction}

A study of government service agencies and nonprofit agencies was performed to assess the array of services provided within Lake County, Indiana, to assess the information technology availability of human services providers throughout the specified area, the potential of incorporating data integration with the collaborative service providers, and to provide recommendations on alternatives for an integrated human service data system. This paper will focus on the technical aspects of integrating client and vendor data with multiple providers of services to the indigent.

\section{Overview, a Four Phase Process}

The project involved a joint venture of Purdue University Calumet and Indiana University Northwest in collaboration with Workforce Development Services of Lake County, Indiana and the Lake Area United Way. The investigators and their project team utilized a four-phase approach to

Material published as part of this proceedings, either on-line or in print, is copyrighted by the author with permission granted to the publisher of Informing Science for this printing. Permission to make digital or paper copy of part or all of these works for personal or classroom use is granted without fee provided that the copies are not made or distributed for profit or commercial advantage AND that copies 1) bear this notice in full and 2) give the full citation on the first page. It is permissible to abstract these works so long as credit is given. To copy in all other cases or to republish or to post on a server or to redistribute to lists requires specific permission from the author. complete their charge. Phase one required interviewing 87 human service providers to include government Township Trustees. The result of this phase enabled the team to identify who the providers of services are and what services they provide.

During phase two, an analysis of the information system capacity of human service providers across the county was performed, as well as an assessment of providers of state and local human service data systems.

In phase three, the investigators sifted through the information collected by the state and local human service providers to propose a minimal common dataset for potential use by all agencies in the County. This common dataset may satisfy a common intake protocol for all agencies.

Finally, in phase four, the delineation of a set of specifications for an integrated human service data system for those agencies surveyed was made. The specifications are based on Internet based technologies for use in the collection, sharing, and analysis of human services data.

\section{Specifics of Phase I}

One-hour interviews were held with 87 executive administrators and/or Information Technology (IT) officers within Lake County, Indiana. Over half of the agencies are classified as non-profit nonreligious organizations, with the rest being a representative sample (governmental, non-profit 
religious, and for profit) entities in Lake County. The following are approximate percents of the top ten areas of service by these agencies: $69 \%$ provide some form of case management, $30 \%$ provide some form of education and/or training, 25\% provide an array of inpatient and/or outpatient mental health services, $21 \%$ provide services targeted to youth, $18 \%$ provide some form of emergency assistance, $16 \%$ provide medical or health related services, $13 \%$ provide shelter services and/or substance abuse services and recreation services, and $12 \%$ provide determination and eligibility assistance. Most providers indicated that they do share information with other agencies, after having their client/recipient sign a proper release of information form.

\section{Specifics of Phase II}

Assessing state and local information technology capacity and infrastructure determined that approximately $40 \%$ of the respondents indicated they had compiled an IT plan. Approximately $20 \%$ of providers indicated they had a dedicated IT staff. However $75 \%$ of the agencies that don't have a dedicated IT staff, indicated that they do have at least one person who spends some of their time on computer related functions. In addition, over $50 \%$ of the responding agencies indicated that they have Internet access, a Website, and an E-mail account. Client and demographic data analysis is performed by $77 \%$ of the reporting agencies. Their primary reason for this reporting is to conform to funding requirements, not for assessing client needs or improving program performance. Even though there is some preliminary documentation related to the proposed integration of IT systems, the State of Indiana has no formal plan in place for the integration of IT systems, using Internet-based technologies.

\section{Specifics of Phase III}

Assessing data collection practices identified three primary data types. See figures 1 through 4 for sample input/display forms. They are applicant information, household information and "other" information. Regarding applicant information, the following attributes were identified by the corresponding percents. Applicant name $(100 \%)$, address $(97 \%)$, phone number $(96 \%)$, date of birth $(88 \%)$, social security number $(81 \%)$, gender $(75 \%)$, marital status $(64 \%)$, race or ethnicity (63\%), emergency contact (70\%), emergency phone number (35\%). On various forms, date of intake was asked by $84 \%$ of the providers, collecting data case number and case worker was requested by over $65 \%$ of the providers. Regarding household information $82 \%$ of the providers collected the following types of data with each corresponding percent: family size (50\%), information about other family members $(57 \%)$. Family member data collected included date of birth, social security number, monthly income and source, and annual income and source. In the "other" types of information category, education/highest degree obtained (53\%), employment status (67\%), place of employment (49\%), and employment phone number (61\%). $80 \%$ of the providers asked for client signatures on a form.

\section{Summary of Phases I through III}

1. Technological development needs to be driven by the primary human service unit involving case management.

2. Lake County agencies are not focused on leveraging the Internet for purposes of both advertising and providing services.

3. The word of mouth referral method suggests that large challenges exist related to educating consumers via Web based media.

4. Agencies do not have well-established practices of interagency collaboration as reflected in the lack of highly structured Memoranda of Understanding.

5. Sharing of data is almost non-existent. Significant hurdles exist related to establishing agreements for sharing information that needs to occur as part of the shift toward integrated information technologies.

6. Most agencies do not have well developed IT plans.

7. Most agencies do not have sophisticated IT staff.

8. Most agencies are not highly capitalized in the area of IT.

9. Most providers do not utilize high capacity Internet resources.

10. Most agencies data analysis activities are relatively unsophisticated.

11. On-line security and confidentiality protocols are a primary challenge in any IT solution.

\section{Specifics of Phase IV}

The following recommendations are part of the identification of a business plan, high-level information technology requirements and related components. 


\section{Human Services Information Technology}

1. The project team and investigators recommend that a county/regional computing environment be developed. It would leverage the low-cost Internet based technologies that are accessible via existing Web browser technology, through local Internet service providers (ISP).

2. The developed system needs to support common access functions through a county/regional Internet portal linked to a dedicated enterprise server.

3. Develop an enterprise server that will have the capability to support common intake/case management functions along with limited data warehousing capabilities. Heterogeneous and homogenous databases from local agencies and providers will be used to develop a countywide data warehouse. This countywide data warehouse may then "share" data with the State of Indiana's welfare systems.

4. Incorporate security and E-commerce methods to model this system to Internet based standards.

5. Utilize middleware (three tier architecture) to balance processing between servers and client computer systems.

6. Components of this new system include a common intake function, master client index, master provider/vendor index, case coordination/management system, legacy system/database interface, E-mail forms automation and referral system, Job search and training/education systems, and secure client access to the system via free standing kiosks and libraries through a virtual private network (VPN).

\section{A Possible Solution, A New Approach}

A key to the success of the proposed service delivery model includes delivering services closer to its clients through a "one stop shopping" approach for the wide array of services offered by Lake County agencies. A major premise of the new model is to give agency staff the information tools they need to help their clients achieve selfsufficiency. This requires the sharing of information on clients, families, vendors, and service suppliers. The core of the new technology will be a Web-based browser enabled common intake function that will provide universal client intake for all Lake County human service clients. The common intake function will aid in avoiding duplicate information gathering by human service agency staff and the repetitive form completion by the County's clients. It will allow the human service agency worker to focus on helping a family to determine a needed service. Appropriate confidentiality of information will be maintained as is ensured under the current, paper-based model.

A Master Client Index (MCI) will be the core of the Common Intake System. All relevant client information will be maintained under a single client identifier on the systemwide MCI. The client information will contain identifying demographic data, family relationship information, consent information, and program participation information. Access to information either stored on the MCI or available through it will be automatically controlled in terms of both security and confidentiality. Access to specific data elements will be controlled independently (i.e., a social service worker might be able to determine that a client has participated in an Income Maintenance program but not a Community Mental Health Center's Drug and Alcohol Program.). Access will be determined on a "need-toknow" basis at the data element level.

The use of a centralized client database (the MCI) implies the definition of a single, countywide identifier. This identifier can be used as well as any program-specific numbers required by State agencies, legacy systems or reimbursement plans. The proposed system identifier will crossreference all known State and County program identifiers to help workers positively identify the Client before them. The Master Client Index will support the requirements of the common intake function with the functionality to provide a centralized and countywide accessible database for storing client demographic information. It will also have the ability to add, change or delete client information either directly on a legacy system, which will update the MCI, or directly via the Common Intake System at the local agency's workstation. The MCI will provide for the automatic creation of audit trail transaction records for determining the origination of a change, addition or deletion to the database. Data security at the data element level will be based on user role definitions as developed by the data base administrator of the MCI.

The following automated and human controlled activities make up the "business plan" of how clients are processed through the system: This system is a clientcentric-based system. The client meets with his/her social service worker and (1) the client/recipient has their database record accessed, if it is available. If not, (2) create or update client's master file record, (3) determine appropriate re- 


\section{Winer and Pavkov}

source(s) to assist the client/recipient, (4) generate E-mail referral, and ticklers, (5) receive referral E-mail and ticklers from E-mailed associate(s), (6) respond to referral Email and ticklers, (7) generate follow-up referral E-mail or tickler, (8) query case history, (9) update case history, (10) determine legacy system updates, (11) update State of Indiana Legacy Systems databases.

The proposed topography of such an integrated system is made up of the following components. Refer to figure 5 for the graphic representation of the hardware component. In order to provide data sharing, and communication necessary to support the identified human services business model, several tools, technologies, vendor products, and application software must be integrated into a cohesive enterprise solution. The components are within the categories of personnel, procedures, hardware (communications and network connectivity), software, and data.

Selection of a database management system (DBMS), such as a relational database management system (RDBMS) or an object oriented database management system

(OODBMS) typically includes considerations such as the volume of data, the need for an integrated development toolset, and the computing platform (e.g., PC, minicomputer or mainframe). While a variety of vendor products are available, the industry has largely focused on the following vendors/products: Information Builders WebFOCUS, Informix, Microsoft's SQL, Oracle, Sybase, and Jeevan (Java) Object Oriented Database. It is common to have a dedicated database server as part of the configured system. It is also recommended that the server be a fault tolerant system with full mirroring of all components. Raid disk technology is also highly recommended for this server.

Middleware is software that connects two otherwise separate applications. For example, there are a number of middleware products that link a database system to a Web server. This allows users to request data from the database using forms displayed on a Web browser, and it enables the Web server to return dynamic Web pages based on the user's requests and profile (security level). Examples of middleware are XML, Java, Powerbuilder, Information Builder's EDA and WebFocus. This type of software may reside on the database server, or on its own dedicated server. A Web server will be used to host the screens/forms that are served to the client during an application session.
E-Mail and messaging tools are vendor products designed to provide messaging, information sharing, and integration capabilities to users in a networked (LAN/WAN) environment. This hardware and software combination can enable messaging and tickler capabilities, as well as sharing client referral history. Assuming that the referral and tickler capabilities can be integrated with an e-mail product, they can provide the messaging capabilities on a dedicated mail server. This is also necessary to allow E-mail to cross the boundaries of disparate E-mail systems. Different vendor products form the basis for an integrated enterprise-wide E-mail system. This capability is also required to provide a backbone for the referral and tickler needs of the multiorganization business units. An E-mail server and E-mail Gateway server will be needed to facilitate these functions.

Network and telecommunication's infrastructure will form the basis for overall connectivity, communications, and network data transmission capabilities to the entire enterprise. This component is typically implemented through a series of local area networks (LAN) and wide area networks (WAN) that together provide the underlying infrastructure for an organization's technology solutions. Paramount to the successful enterprise-wide connectivity between the business units is that each business unit is responsible for gaining its own access to the Internet. Once the business unit connects to the Internet, it can log onto the enterprise system and perform its job functions. Depending on how the enterprise system is configured, it may also be prudent to have a dedicated DNS server. The Internet then becomes the conduit that connects all units together. It is highly recommended that a Virtual Private Network (VPN) be developed to support the added level of security that is necessary. Additional hardware and related software for this component are also needed. In addition to the VPN, a firewall server and an enterprise Web Server, there is a need for each business unit, that has multiple users on their LAN or WAN to purchase routers and/or DSUCSU devices at their business unit's sites. However, if the business unit is only using a single PC to access the enterprise system, they may purchase a modem and a dedicated Internet connection from their local Internet service provider (ISP).

\section{Conclusion}

The technical feasibility of a project such as this is proven to be capable of being successfully implemented. However, in addition to cost constraints of governmental and non-profit agencies, there is also the political constraint of personnel within the organizations and the political party 


\section{Human Services Information Technology}

form of political constraints. The challenge to successfully implement such a huge intergovernmental/private for profit and non-profit information technology project is just as much one of human related issues as it is technology issues.

\section{Biographies}

Charles Winer is an associate professor at Purdue University Calumet, where he teaches database and senior capstone courses in the Information Systems and Computer Programming department. Professor Winer has authored several papers on database systems, e-commerce and distance learning. In addition, he recently presented a keynote plenary address on The Internet, E-Commerce \& Database Methods at the $5^{\mathrm{TH}}$ World Multiconference on Systemics, Cybernetics and Informatics (SCI) \& Information Systems Analysis and Syntheses (ISAS) Conference 2000 in Orlando, Florida

Thomas Pavkov is Director of the Head Start XXI Resource Center and an Associate Professor of Psychology. Dr. Pavkov has served as an academic advisor and instructor in the areas of statistics, research methods, child
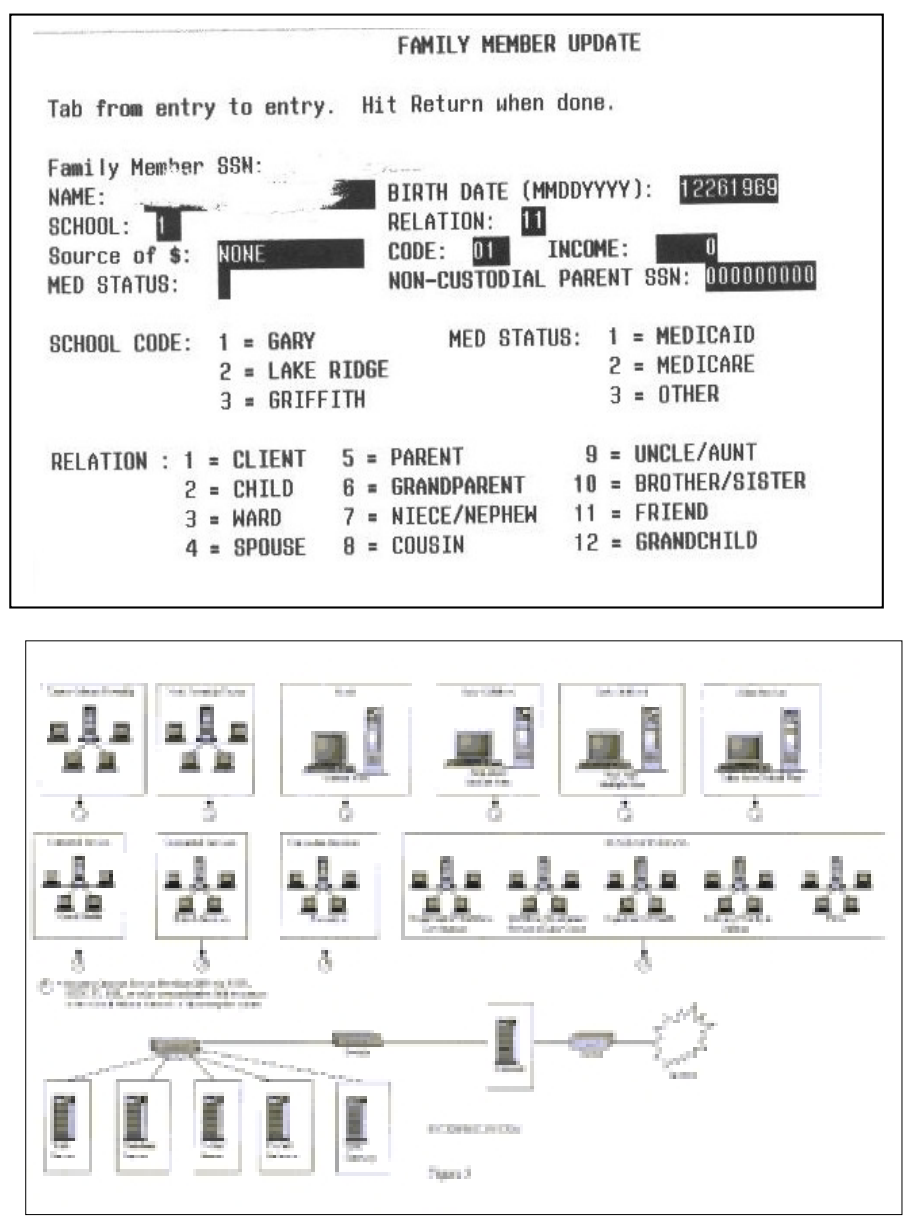

development, and adolescent development. He is also a research associate with the Chapin Hall Center for Children at the University of Chicago. In addition, he directs the operations of the Lake County Child Care Resource and Referral, and is the Evaluation Director for the Child Mental Health Initiative for Northwest Indiana.

Figures 1 though 5 follow.

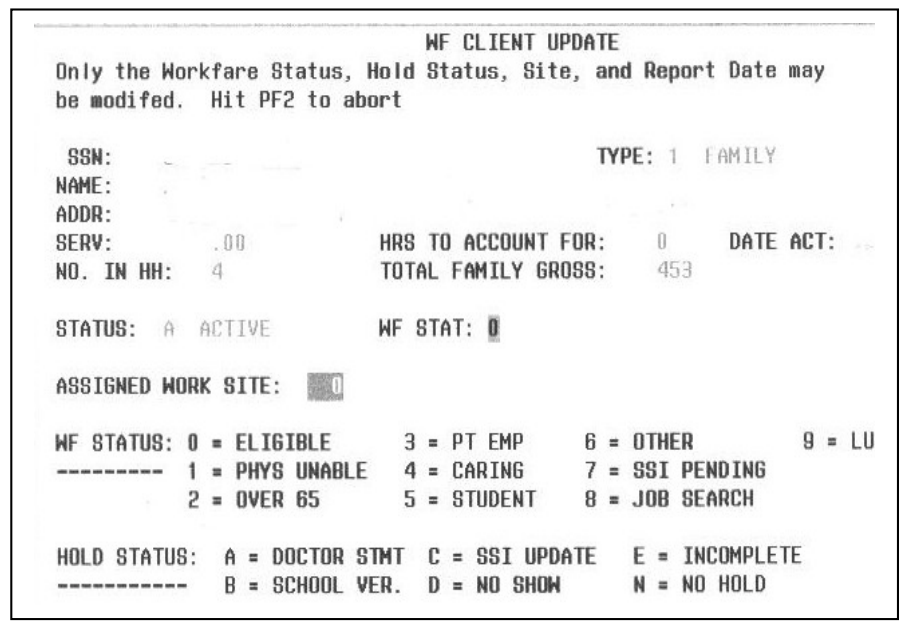
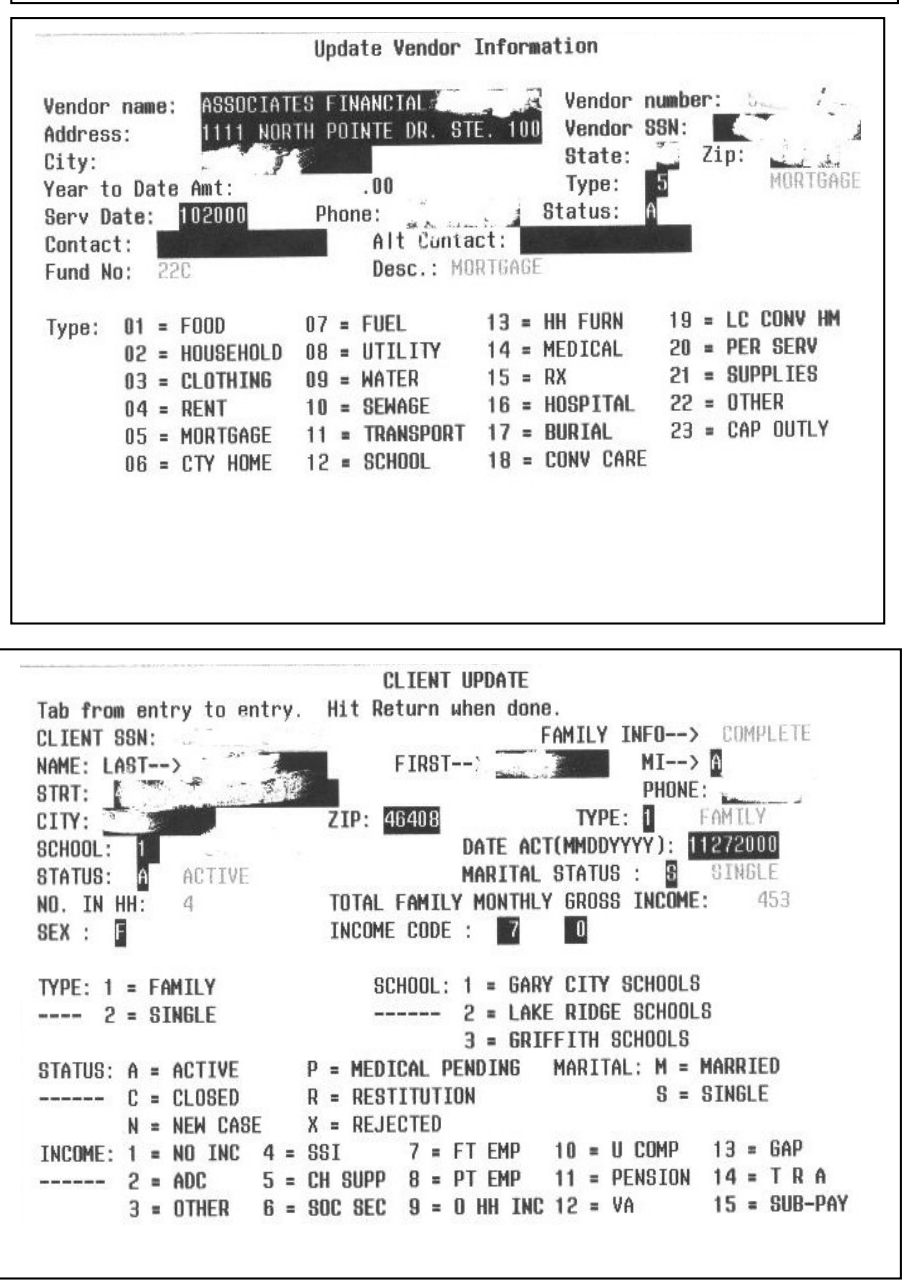